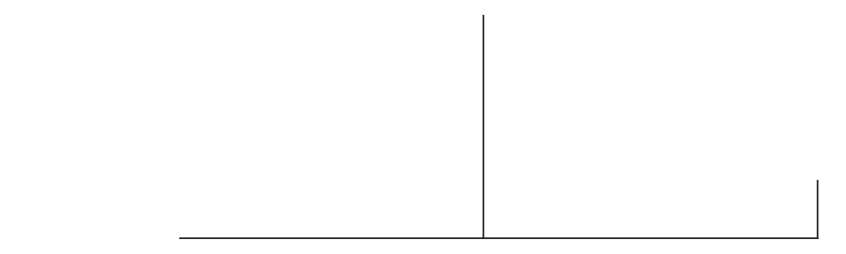

Rev. Latinoam. Psicopat. Fund., III, 1, 183-188

Michel Foucault. Problematização do sujeito:

Psicologia, psiquiatria e psicanálise

Manoel Barros da Motta (org.)

Rio de Janeiro, Florense

2000

\title{
Michel Foucault. Problematização do sujeito
}

\author{
Chaim Samuel Katz
}

Pensar as relações de Michel Foucault (1926-1984) com os saberes psis, que é para onde nos reclama este livro, exige um compromisso de muitas direções. Enquanto psicanalista, penso ser insuficiente (apesar de necessária) a observação de Jacques Derrida acerca da oscilação foucaultiana por relação à psicanálise: $1^{\circ}$ ) desde a inexistência da unidade de nosso saber, e $2^{\circ}$ ) pelas diferenças entre a potência de pensamento psicanalítico e sua produção instituída. Nossas diferenças institucionais e de organização não se eliminam pela teoria.

Desde seu primeiro escrito mais amplo, a introdução ao "O sonho e a existência” de Ludwig Binswanger (1954), Foucault questionou a unidade das psicologias e da psicanálise. Lembro que era a época em que Daniel Lagache postulava que as psicologias eram uma (“A unidade da psicologia”, 1949) e Lacan já ensaiava unificar o saber freudiano exclusivamente no campo das teorias da linguagem ("Função e campo da fala e da linguagem em Psicanálise”, 1953). Foucault criticava ambas, pois não considerariam o estatuto do ser-homem (Menschsein) e sua concretude existencial. Questionava Freud pela ausência de uma teoria das imagos e pela afirmação do Desejo como "teologia das significações na qual a verdade se antecipa à sua formulação e a 


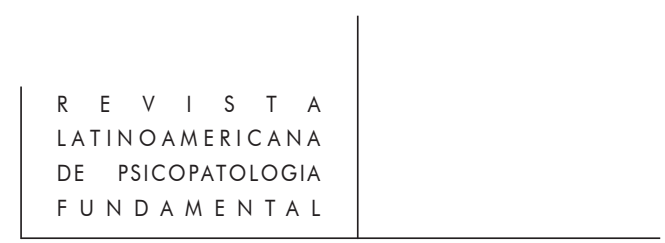

constitui inteiramente” (p. 70). O que acarretava também a ausência de verificar o ato expressivo em sua necessidade efetiva.

Sempre achei que isto significou uma diferença especial com Lacan e não com toda a psicanálise freudiana, que não ignorou a especificidade das imagos e expressões (ver o caso Cäcilie, por exemplo). O Desejo da tradição filosófica francesa tem uma filiação marcada desde os ensinamentos do filósofo russo Kojéve, sobre a Begierde hegeliana (a mesma noção foi absorvida por Binswanger), que resultou na determinação psicanalítica do sujeito por relação à cadeia significante, no regime da Falta, a sexualidade se constituindo sem corpo, por meio da Begierde. Enquanto, em Freud, o desejo é Wunsch, delineado pelo impulso de realizar uma fantasia inatingível, sempre de ordem da sexualidade, envolvendo o corpo e sua erogenidade. O que conduz a diferenças teóricas e clínicas importantes.

Nesse mesmo ano, Foucault publicou seu primeiro livro, Doença mental $e$ personalidade. Um de seus temas mostra que o homem só se considerava racional se pudesse ser inscrito na normalidade socialmente aceita. Ele terminava seu escrito criticando a psicologização das categorias do adoecer, afirmando que era preciso ligar o homem às suas condições sociais reais de vida: a "verdadeira psicologia deve livrar-se deste psicologismo, se é verdade que, como qualquer ciência do homem, ela tem como finalidade desaliená-lo".

Contudo, na segunda edição desse livro (que passou a se chamar de Doença mental e psicologia), ele se deu conta de que incidia naquilo que criticava: se as diferenças se davam por relação aos concretos culturais, o que acontecia com os que eram distintos numa mesma cultura? Todas as culturas e grupos excluem pensamentos e comportamentos insanos e/ou desrazoados. Ao mesmo tempo, estes produtos psíquicos se apresentam, enquanto multiplicidade e diferença, em todos os grupos e também nos indivíduos assujeitados. Não se tratava então e apenas, concluiu Foucault, de pensar as diferenças culturais, mas de estabelecer que fundamentos permitem a emergência de uma norma que regula tais portamentos, um conjunto de conhecimentos que se estabelece como saber verdadeiro, e porque certos pensamentos são dele excluídos. Ou seja, não se tratava mais de analisar a organização psicológica ou existencial das personalidades, mas da abordagem dos mecanismos que permitiram a emergência e a constituição científica das psicologias, estes saberes que estudam cientificamente e determinam os destinos de tais personalidades.

Ainda, perguntar por que tais saberes sobre o psiquismo se põem como verdades exclusivas a respeito do ser do homem, considerando apenas aquilo que está do lado da medida e da ordem, do racional. Tal questão, grave e fundamental, tem como fundo a afirmação de Nietzsche, que Foucault escreveu no manuscrito do Doença mental: "Existem três experiências vizinhas: o sonho, a embriaguez e a in- 
sensatez” (p. 9). O que aponta para experiências psíquicas importantes e diferenciadas, sempre desconsideradas no Ocidente, por suas características a-racionais ou irracionais.

É neste trajeto que verifico a passagem de Foucault da questão da cura das doenças mentais para a fundamentação da loucura. O próximo passo está na sua História da loucura na Idade Clássica, que se chamou originalmente de Loucura e desrazão (1957).

Deve-se pensar se isto se insepara da vida de Foucault. Os fatos de sua chamada "vida privada" raramente se publicam, apesar de ele ter nos falado deles com vigor. Como se aprende com a sua "Cronologia" nesse livro, ele não tinha ficado contente com sua "escolha" homossexual. Bebia muito, dedicou-se às drogas, experimentou fazer três terapias (entrevista para a falecida revista Versus e relato pessoal), pediu ao seu pai que o internasse, tentou o suicídio duas vezes. Mas sei que tais experiências trágicas, perpassando os limites entre razão e desrazão, ajudaramno, não apenas a ser um grande pensador, mas um homem sumamente generoso, acolhedor de múltiplos gêneros. Foi participante ativo e fundador de inúmeros grupos, acerca das condições dos presos, dos asilados, dos pobres, homossexuais e imigrantes; defendeu judeus do anti-semitismo e árabes do sionismo. Interveio abertamente nas relações dos médicos com seus pacientes, de psiquiatras com seus asilados. Foi preso inúmeras vezes na França e no estrangeiro, participando de manifestações libertárias. No Rio de Janeiro, num momento político muito grave, em 1974, no auge da repressão militar e das ameaças explícitas aos membros da Clínica social de psicanálise, me entregou uma carta para Kathrin Kemper, que publicamos, louvando a excelência e a exceção de nosso trabalho social, de cujo interesse duvidava. $\mathrm{O}$ que nos deixou menos sujeitos às ameaças fascistas e dedoduras das sociedades ligadas à Internacional Psicanalítica (IPA).

Isto o levou (cf. a aula inaugural, no Collège de France, em 1983) a enunciar, de acordo com Kant, a importância do agora, do presente para os discursos e expressões. Que diriam respeito a um "nós” muito específico, "um certo 'nós', a que se refere um conjunto cultural característico de sua própria atualidade”. Propugnando encontros atuais, em torno de interesses (inter, esse, entre o ser) comuns.

Espero que nenhum luminar conclua que estou dizendo que Foucault foi grande pois desrazoável, pois o que afirmo é que ele fez de sua vida uma passagem possível, no seu registro trágico vibrante e arriscado, do que se constituiu, na última parte de sua obra, uma ética-estética da existência.

A partir desse seu grande primeiro livro sobre a história da loucura, aprendemos como o Ocidente excluía o que ameaçava. Se tínhamos sabido com Hegel (17701831), o filósofo maior da codificação, que a Razão constituía uma grande unidade, que os loucos também pertenciam a ela, apenas tinham ficado numa etapa insuficiente 
dos desdobramentos do Espírito Absoluto (à moda de uma "consciência infeliz"), Foucault ensinou, por meio do exame de documentos e teorias historicamente concretos, que havia expressões psíquicas muito poderosas que não se assujeitavam a um grande e único Logos. Enquanto a psiquiatria francesa libertária tinha seus dois grandes heróis, Pinel (1745-1826) e Esquirol (1772-1840), como modelos da experiência de incluir os loucos na vida social normativa, pelo seu asilamento liberal, Foucault mostrou uma especificidade da loucura, que a Razão (teórica, social, institucional) não podia aceitar, sob pena de ser destruída por dentro.

Ele nos ajudou a pensar no regime trágico da loucura, desde que o desrazoável não faz nexos ou portamentos permanentes e estáveis. Mostrou como esta questão não se resolvia com sua transformação em doença mental, psiquiatricamente catalogada. Tal apropriação médica da loucura terminou por transformar também a Medicina e a Psiquiatria e suas percepções, situando-as como saberes que tinham, doravante, poder de determinar os dizeres e fazeres doentes que precisariam ser normalizados. Estudando concretamente esta história no Ocidente, ensinou que desde a percepção das questões postas pela loucura, até seu isolamento e apropriação pelos saberes e práticas psiquiátricos, a loucura, tornada insanidade mental, será considerada homogeneamente, a fim de se instalar no campo adequado das medidas, de uma ratio externa que experimenta enquadrá-la e curá-la, normalizando-a.

Acerca deste ponto, Foucault reconheceu suas semelhanças com o pensamento freudiano. A loucura pode vir a se transformar em doença mental e seus sintomas eliminados ou neutralizados, "mas uma coisa permanecerá: a relação do homem com seus fantasmas, com seu impossível, com sua dor sem corpo, com sua carcaça da noite; uma vez posto fora de circuito, o patológico, a sombria pertença do homem à loucura será a memória sem idade de um mal apagado em sua forma de doença, mas obstinando-se como desgraça” (p. 191). É neste mesmo texto ("A loucura, a ausência da obra”) que ele reconhece uma especificidade do fazer freudiano. Que não recorre a alguma experiência psicológica comum externa ao louco (como no chamado tratamento moral) ou a alguma cadeia significante onde o sujeito se constituísse necessariamente, mas é uma clínica que permite a insistência de uma fala (parole, que a tradutora insiste em apresentar como "palavra", mot) sobre si mesma, até dissecá-la de um pretenso Logos que a constituiria. É por isto que Foucault situará Freud permanentemente entre os poucos que fizeram uma "escolha original", escolha "que delimitaria todo o conjunto constituído pelo saber humano, as atividades humanas, a percepção e a sensibilidade” (p. 212).

Não se trata de investigar, à moda hegeliana, as contradições e dificuldades discursivas por relação à Razão ou a um Simbólico organizador, mas procurar a linguagem no seu regime expressivo insistente e que se dobra sobre si mesmo, considerando que a loucura é um regime específico de linguagens e fazeres. E é disto que importa também na psicanálise freudiana que interessa e que aprendemos 
com vigor desde o texto freudiano sobre o indomesticado (Freud 1919h, Das Unheimliche).

Onde Foucault e os psicanalistas nos diferenciamos, é no estatuto inegavelmente sexual da loucura, o que não cabe discutir aqui. Considerando que a sexualidade não se refere à linguagem incitadora dos atos sexuais, mas diz respeito ao corpo e à organização da repetição, pode-se começar a entender porque muitos psicanalistas fomos levados a estudar "uma matriz da linguagem que, em sentido estrito, não diz nada. Dobra do falado que é uma ausência de obra” (p. 196). E a agi-la clinicamente. Outro passo de Foucault é se indagar sobre os poderes que se manifestam no aparelho psiquiátrico (p. 291, por exemplo). Mostrou que a produção contemporânea da verdade é devedora da produção de confissão, tratando-se de consegui-la também dos loucos: “que ser sexual é você?”, tal seria uma enorme questão dos saberes humanos na contemporaneidade. E, seguindo Foucault, isto incluiria a psicanálise.

Resumindo, a loucura diz respeito a um existente, que tem (pelo menos) um duplo registro. Existente, que se manifesta pelo "apelo para as rupturas e cortes abruptos, para a enorme dificuldade de conjunção e articulação, que remete para almejar o impossível, à suspensão parcial de níveis de realidade, para o chamado mais agudo e constante da disjunção e da destruição, e da compulsão incessante à repetição; cria níveis de realidade singulares e individuais, possibilita o domínio do psiquismo por fortes experiências dispersivas ou excessivas de sentidos múltiplos, inscreve experiências psíquicas no registro corporal imediato, implica no exame minucioso e repetido de situações que passam desapercebidas no cotidiano" (CSK). Mas, segunda faceta, a loucura se acompanha das imagens e valores que se tem dos loucos, bem como dos saberes que os determinam enquanto doentes mentais. Não é possível insistir mais aqui, mas a loucura nos remete à experiência da morte e da finitude humanas. Como o próprio Foucault disse: "O que tira a existência humana dos eixos são este acabamento e esta ordem, dos quais nada escapa. A presença que ameaça no próprio interior do mundo é uma presença desencarnada". Se antes o que ameaçava os sujeitos ocidentais eram a lepra ou a sífilis, "a substituição do tema da loucura pelo da morte não marca uma ruptura, mas antes uma torção no interior da mesma inquietude".

Bem, é isto que levará Foucault a postular, num outro livro, o que ele denominou a episteme, um regime de regularidades discursivas, condição para a percepção e a constituição dos pensamentos. E que no século XX, marcado pelos saberes empíricos, tal saber inconsciente se constitui de três elementos, a Morte, o Desejo e a Lei. Episteme invisível, marcada pela finitude e imanência, de cujos constituintes as representações não dão conta. Aí se deve ouvir a voz dos loucos, que dialogam de modo especial com estes três elementos. E dá um lugar privilegiado à psicanálise, que, tendo "por tarefa fazer falar o discurso do inconsciente através da consciência, 


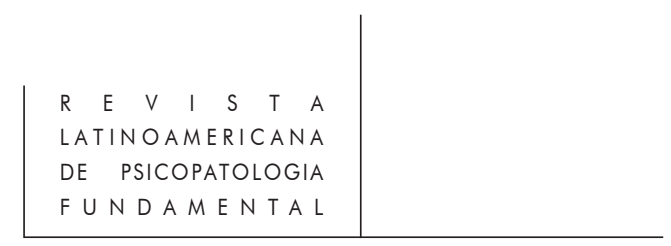

avança na direção desta região fundamental onde se jogam as relações da representação e da finitude"1.

Enquanto psicanalista, acredito que o exame da "experiência da loucura” tem marcas distintas de outras experiências, como as da lepra, da peste, das doenças venéreas, à medida que a loucura remete à morte permanentemente (é isto que se aprende com a elaboração freudiana da pulsão de morte). Ou, quem sabe, deveria dizer com um certo Foucault que faço tal afirmação pois me encontro no interior de uma episteme que se constitui "de morte". Enquanto outro Foucault - que me interessa mais - me ensina que a finitude e seus dizeres requerem a expressão permanente e "dobrada" de seus enunciados: modo de escapar da morte, que é um limite inalcançável enquanto símbolo. A morte só (não) se alcança por uma interpretação, seguida de outra interpretação, infinitamente... É nisto que ele caracterizou a especificidade de Nietzsche, Marx e Freud, como pensadores que mostraram os limites da representação.

Pensei que a "Apresentação" brasileira poderia ter sido mais cuidadosa, elaborando as passagens no pensamento foucaultiano, à medida que não seguiu a cronologia da edição francesa. A anunciada (no título) "problematização do sujeito" não se realiza; pouco se aprende acerca de sujeito e subjetivação em Foucault no texto de introdução. Para uma próxima edição, faz-se necessária a revisão. Anoto, entre os nomes mal grafados, Solelrs ou Sallers, Samprun, Khomeimi, Falge, Konchner, Cacicles, Novalia, Empédocle ao invés de Sollers, Semprun, Khomeini, Farge, Kouchner, Cálicles, Novalis, Empédocles; Auchwitz em vez de Auschwitz. Para dizer a cassação política, na página 18, "caçar" em vez de "cassar”; "Gegonwirken" em vez de "Gegenwirken", "macht” em vez de "Macht", "transistórica", caximbo, "hei-lo" etc. O leitor que procura elementos concretos, sai mal informado. Foucault, pensador das pequenas concretudes e elegante escritor, não teria gostado.

1. Michel Foucault. Les mots et les choses, une archéologie des sciences humaines. Paris: Gallimard, 1966, p. 385. 